\title{
Synthesis, characterization, and activity of a covalently anchored heterogeneous perylene diimide photocatalyst
}

\author{
Jinting Shang a,b, Hanying Tang a,b, Hongwei Ji a,b, Wanhong Ma a,b, Chuncheng Chen a,b,*, Jincai Zhao a,b \\ a Key Laboratory of Photochemistry, CAS Research/Education Center for Excellence in Molecular Sciences, Institute of Chemistry, Chinese Academy of \\ Sciences, Beijing 100190, China \\ b University of Chinese Academy of Sciences, Beijing 100049, China
}

\section{A R T I C L E I N F}

\section{Article history:}

Received 18 October 2017

Accepted 1 November 2017

Published 5 December 2017

\section{Keywords:}

Visible light

Photocatalysis

Nanosilica

Perylene diimide

Debromination

\begin{abstract}
A B S T R A C T
The consecutive two-photon photocatalytic behavior of perylene diimide (PDI) enables it to catalyze photoreduction reactions that are thermodynamically unfavorable via single-photon processes. In this work, we developed a heterogeneous PDI photocatalyst by covalently binding PDI molecules on the surface of nanosilica. This photocatalyst structure overcomes the intrinsic limitation of the low solubility of PDI, but retains its consecutive two-photon photocatalytic property. Detailed characterization of the photocatalyst by techniques such as thermogravimetric analysis, solid-state nuclear magnetic resonance spectroscopy, and Fourier transform infrared spectroscopy indicated that the PDI molecules were anchored covalently on the surface of nanosilica. The obtained photocatalyst reduced aryl halides under visible-light irradiation in polar organic solvent and in water. The present study provides a promising strategy to realize two-photon activity of PDI in common solvents for photocatalytic applications.
\end{abstract}

(C) 2017, Dalian Institute of Chemical Physics, Chinese Academy of Sciences. Published by Elsevier B.V. All rights reserved.

\section{Introduction}

The photocatalyst is essential in photocatalytic reactions. Inorganic photocatalysts such as $\mathrm{TiO}_{2}$ [1-3] have played a leading role in past photocatalysis studies. However, satisfactory photocatalytic efficiency has still not been reached even after a long, thorough investigation of inorganic photocatalysts. Therefore, many researchers have turned their attention to the development of organic photocatalysts [4]. Compared with inorganic photocatalysts, organic materials have many advantages, for example, their strong visible-light adsorption, cheap and abundant element resources, and structural tunability. Various organic photocatalysts have been reported including pure organic dyes [5], organometallic complexes [6,7], and covalent organic polymers such as carbon nitride [8,9] and poly ( $p$-phenylene) $[10,11]$. While each pure catalyst has associated limitations, they may be overcome by using a combination of catalysts [12-15].

Perylene-3,4,9,10-tetracarboxylic diimide (PDI) has unique optical and electronic properties, such as high oxidation potential, high molar extinction coefficient, and good thermal and photochemical stability $[8,16]$, and thus has been widely used as a basic structural unit to fabricate organic photofunctional materials for applications such as fluorescent sensors [17-19]. PDI has also been used as a photocatalyst to realize photoinduced chemical transformation. It was recently reported that the excitation of PDI by visible light produces a PDI radical anion, which can absorb another photon [20]. The excited state of

\footnotetext{
* Corresponding author. E-mail: ccchen@iccas.ac.cn

This work was supported by the National Natural Science Foundation of China $(21525729,21590811,21521062,2177168)$, the "Strategic Priority Research Program" of the Chinese Academy of Sciences (XDA09030200), and the "CAS Interdisciplinary Innovation Team Program". DOI: 10.1016/S1872-2067(17)62960-7 | http://www.sciencedirect.com/science/journal/18722067 | Chin. J. Catal., Vol. 38, No. 12, December 2017
} 
the radical anion accumulates the energy of two photons and can then reductively cleave the $\mathrm{C}-\mathrm{X}$ bond of aryl halides. This consecutive two-photon reaction can promote photoreduction reactions that are thermodynamically unfavorable as a single-photon process (such as the cleavage of the $\mathrm{C}-\mathrm{X}$ bond of stable aryl halides), making PDI promising as a visible-light photocatalyst for use in reactions with low activity. However, because of the intrinsic hydrophobicity of PDI, these reactions have to be carried out in organic solvents [21]. Most PDI derivatives have very low solubility and a strong tendency to aggregate in common organic solvents. Therefore, it remains desirable to realize photocatalytic reactions using PDI in common organic solvents, or even in water, which is the most environmentally friendly solvent. PDI may be loaded on semiconductor oxide $\left(\mathrm{WO}_{3}, \mathrm{TiO}_{2}\right.$, or $\left.\mathrm{SnO}_{2}\right)$ surfaces via aggregation/hydrophobic forces [22] or form self-assembled supramolecular nanostructures [23] to enable its photocatalytic reactions to be carried out in polar solvents or water. However, the two-photon activity of PDI is lost in such systems because of the electronic interactions of PDI and the semiconductor or between PDI molecules. To avoid these interactions, PDI has been incorporated into a metal-organic polymer [24]. This approach achieved efficient reduction of aryl halides by the consecutive two-photon process.

Herein, we develop a novel strategy to realize the heterogeneous two-photon photocatalytic activity of PDI by covalently anchoring PDI on non-conductive nanosilica (nano- $\mathrm{SiO}_{2}$ ). In this hybrid photocatalyst (denoted as SN-PDI), the binding of $\mathrm{PDI}$ to the nano- $\mathrm{SiO}_{2}$ surface avoids the interaction between PDI molecules. The high hydrophilicity of nano- $\mathrm{SiO}_{2}$ makes the SN-PDI photocatalyst miscible with polar solvents. As a result, efficient photocatalytic reduction of aryl halides is achieved in aqueous solution.

\section{Experimental}

\subsection{Materials}

Aminopropyltriethoxysilane (APTES), 3,4,9,10-perylenetetracarboxylic dianhydride (PTCDA), triethylamine (TEA), decabromodiphenyl ether (BDE 209), and 4-bromoacetophenone (4-BCP) were purchased from Alfa Aesear. Tetraethoxysilane (TEOS) was obtained from Xilong Chemical Co., Ltd. Sodium sulfide $\left(\mathrm{Na}_{2} \mathrm{~S}\right)$ was supplied by J\&K. All materials were used as received.

\subsection{Synthesis of nanosilica-supported PDI (SN-PDI) photocatalyst}

\subsubsection{Preparation of nanosilica with surface amino groups $\left(\mathrm{SN}-\mathrm{NH}_{2}\right)$}

Nanosilica with surface amino groups $\left(\mathrm{SN}-\mathrm{NH}_{2}\right)$ was synthesized by co-condensation of APTES and TEOS according to Rahman's method [25]. Briefly, TEOS (40.5 mmol) and APTES (162 mmol; molar ratio of 1:4) were added to ethanol (225 $\mathrm{mL}$ ). After stirring magnetically for $10 \mathrm{~min}, \mathrm{H}_{2} \mathrm{O}(8 \mathrm{~mL})$ was added to initiate the co-condensation by hydrolysis. Reaction for $3 \mathrm{~h}$ led to the formation of a white suspension. The opaque suspension was filtered and washed three times with ethanol. Finally, the post-filtration product $\left(\mathrm{SN}-\mathrm{NH}_{2}\right)$ was dried at 120 ${ }^{\circ} \mathrm{C}$ for $24 \mathrm{~h}$ [26].

\subsubsection{Preparation of $S N-P D I$}

A mixture of SN-NH $\mathrm{N}_{2}$ (0.7 g), PTCDA (0.5 g), and imidazole (5 g) was heated to $150{ }^{\circ} \mathrm{C}$ under nitrogen and stirred magnetically for $48 \mathrm{~h}$. In this reaction process, the basic imidazole first catalyzes the cleavage of the anhydride groups of PTCDA, and then the formed diacid reacts with the amino groups on the nano- $\mathrm{SiO}_{2}$ surface to generate an imide. As a result, PDI was anchored on nano- $\mathrm{SiO}_{2}$ (Scheme 1). Upon cooling to room temperature, ethanol $(50 \mathrm{~mL})$ and concentrated hydrochloric acid (12 mol/L, $30 \mathrm{~mL}$ ) were added to form diimide groups. After stirring overnight, a red powder was obtained following vacuum filtration through a $0.45-\mu \mathrm{m}$ membrane filter. The powder was washed three times with $200 \mathrm{~mL}$ of an aqueous solution of potassium hydroxide ( $20 \mathrm{~g}$ ) and potassium chloride (16 g) to remove the residual PTCDA. Subsequently, the red solid was added to $10 \%$ hydrochloric acid solution and stirred for $6 \mathrm{~h}$ to neutralize the residual base. The solid was filtered, washed with water, and then dried at $90{ }^{\circ} \mathrm{C}$ in a vacuum oven, providing $0.92 \mathrm{~g}$ of SN-PDI.

\subsection{Characterization}

Transmission electron microscopy (TEM; JEM-2010, JEOL, Japan) was conducted at an accelerating voltage of $120 \mathrm{kV}$. The TEM specimen was obtained by dissolving the sample in ethanol and added the solution dropwise onto a copper grid. Scanning electron microscopy (SEM; S-4300F, JEOL) was performed at $5 \mathrm{kV}$. The sample was dispersed in ethanol and added dropwise onto a conductive copper adhesive before sputtering approximately $3 \mathrm{~nm}$ of platinum on the surface. X-ray photoelectron spectroscopy (XPS; 220i-XL, ESCALab) was measured at a base pressure of $3 \times 10^{-9}$ mbar.

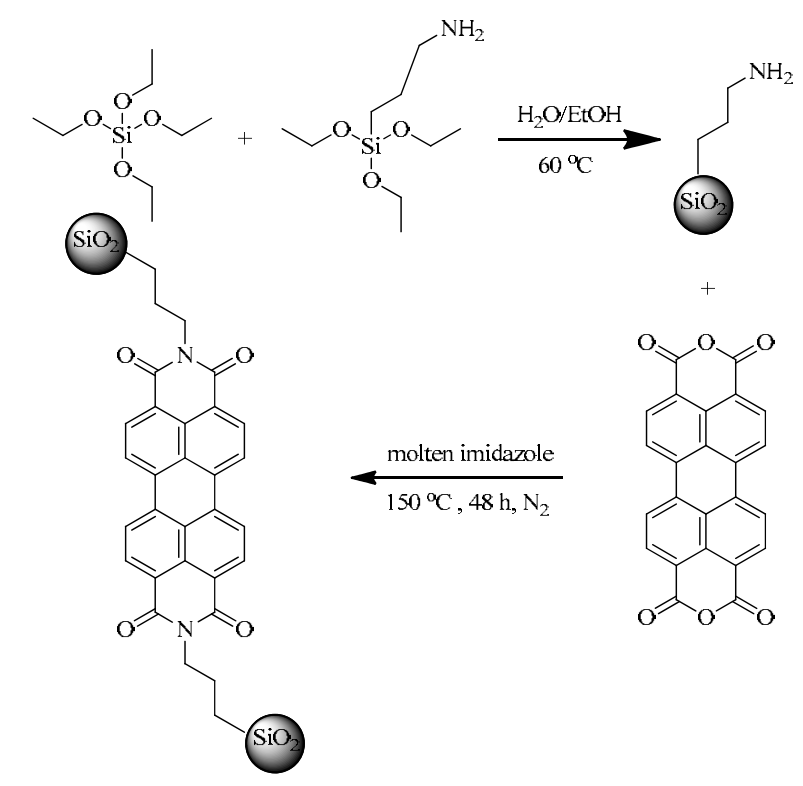

Scheme 1. Synthetic route to SN-PDI. 
Thermogravimetric analysis (TGA) was performed on Perkin-Elmer Pyris 1 and TGA 7 thermogravimetric analyzers in nitrogen and air atmospheres, respectively. Solid samples were heated from 100 to $750{ }^{\circ} \mathrm{C}$ at a rate of $20^{\circ} \mathrm{C} / \mathrm{min}$. Brunauer-Emmett-Teller (BET) and total pore volume (TPV) analyses were conducted using Quantachrome Instruments software (version 11.0). Data acquisition and reduction were performed with NOVA Instruments equipment (1994-2010). Nitrogen was used as the analysis gas, the bath temperature was $77.3 \mathrm{~K}$, and samples were analyzed for $567 \mathrm{~min}$.

Solid-state nuclear magnetic resonance (SSNMR) spectroscopy was conducted on a Bruker Avance III 400 NMR spectrometer. The samples were added into a zirconia rotor $(d=4$ $\mathrm{mm}$ ) and then the rotor was sealed and loaded in the spectrometer. ${ }^{29} \mathrm{Si}$ magic angle spinning (MAS) NMR spectra and ${ }^{13} \mathrm{C}$ cross-polarization (CP) MAS NMR spectra were measured. The spinning speed, pulse length, recycle delay, and accumulated number for ${ }^{29} \mathrm{Si}$ MAS NMR spectra were $8 \mathrm{kHz}, 4 \mu \mathrm{s}, 10 \mathrm{~s}$, and 10240 times, respectively, while those for ${ }^{13} \mathrm{C}$ CP MAS NMR spectra were $8 \mathrm{kHz}, 3.0 \mathrm{~ms}, 2.0 \mathrm{~s}$, and 10240 times, respectively.

Fourier transform infrared (FT-IR) spectroscopy was performed using a Perkin-Elmer System 2000 spectrometer. The wavenumber range was $4000-650 \mathrm{~cm}^{-1}$ and the samples were dispersed in potassium bromide tablets. Ultraviolet-visible (UV-vis) absorption spectroscopy was carried out on a UV-vis spectrometer (Hitachi High-Technologies Corporation).

\subsection{Determination of product distribution}

BDE 209 and its reductive products were analyzed by electron capture detection gas chromatography (ECD-GC; Agilent Technology, 7890A) with an HP-5 column $(30 \mathrm{~m} \times 0.25 \mathrm{~mm})$. Helium was used as the carrier gas at a constant flow rate of 1.0 $\mathrm{mL} / \mathrm{min}$. The oven temperature was kept at $100{ }^{\circ} \mathrm{C}$ for $2 \mathrm{~min}$, increased at a rate of $15{ }^{\circ} \mathrm{C} / \mathrm{min}$ to $230{ }^{\circ} \mathrm{C}$, then at $5{ }^{\circ} \mathrm{C} / \mathrm{min}$ to $270{ }^{\circ} \mathrm{C}$, and finally increased at $10^{\circ} \mathrm{C} / \mathrm{min}$ to $330^{\circ} \mathrm{C}$ for $8 \mathrm{~min}$. The amounts of 4-BCP and its reductive products were analyzed by high-performance liquid chromatography (HPLC; Agilent Technology, G1328B) with a Diamonsil C18(2) column (5- $\mu \mathrm{m}$ particles, $250 \times 3.0 \mathrm{~mm}$ ). The mobile phase was $45 \%$ water in acetonitrile, the flow rate was $0.2 \mathrm{~mL} / \mathrm{min}$, and the detector wavelength was $240 \mathrm{~nm}$.

\subsection{Photocatalytic activity experiments}

Reaction dispersions were prepared by adding SN-PDI (10 $\mathrm{mg}$ ) to DMF or water $(10 \mathrm{~mL})$ containing aryl halides in a Pyrex vessel. TEA ( $1 \mathrm{mmol} / \mathrm{L}$ ) or another reductive agent was added to the dispersions as an electron donor. The Pyrex vessel was sealed and purged with argon gas for 30 min to remove oxygen and protected under argon atmosphere during irradiation. During the photoreaction process, the reactor was kept at $25^{\circ} \mathrm{C}$ by a water circulating bath (HX-205, Beijing YKKY Technology Co., Ltd). A xenon lamp (PLS-SXE300, Beijing Trusttech Co. Ltd.) with a cut-off filter of $\lambda>420 \mathrm{~nm}$ was used as the light source. At given time intervals, $0.5-\mathrm{mL}$ aliquots were removed, centri- fuged, and then filtered through a Millipore filter (pore size: $0.20 \mu \mathrm{m}$ ) to remove the photocatalyst particles. The filtrates were analyzed by HPLC and ECD-GC.

\section{Results and discussion}

\subsection{Characterization of $\mathrm{SN}-\mathrm{NH}_{2}$ and $\mathrm{SN}-\mathrm{PDI}$}

The TEM and SEM images in Fig. 1 reveal that SN-NH2 consists of irregular spherical particles with a diameter of about 40 nm. The energy-dispersive X-ray (EDX) profiles confirm the presence of $\mathrm{C}, \mathrm{N}, \mathrm{O}$, and $\mathrm{Si}$ in $\mathrm{SN}-\mathrm{NH}_{2}$. Loading PDI did not appear to change the morphology of nano-SiO ${ }_{2}$, implying that PDI was loaded as molecules on the surface of nano- $\mathrm{SiO}_{2}$ rather than forming aggregates. The BET measurements show that $\mathrm{SN}-\mathrm{NH}_{2}$ has a surface area of $72.2 \mathrm{~m}^{2} / \mathrm{g}$, whereas that of SN-PDI is considerably lower $\left(39.9 \mathrm{~m}^{2} / \mathrm{g}\right.$, Table 1$)$.

The XPS survey scans (Fig. 2(a) and (b)) contained peaks at binding energies of around 531, 399, 285, and $103 \mathrm{eV}$ that are attributed to $01 s, \mathrm{~N} 1 s, \mathrm{C} 1 s$, and $\mathrm{Si} 2 p$, respectively. The main difference between the XPS scans for SN-NH2 and SN-PDI is the shift in the N $1 s$ binding energy from 399.1 to $399.9 \mathrm{eV}$ (Fig. $2(\mathrm{c})$ ), revealing that $\mathrm{N}$ is in different environments in the two samples. The XPS and EDAX analyses indicate that the atomic ratio of C in SN-PDI is larger than that in $\mathrm{SN}-\mathrm{NH}_{2}$, while that of Si decreases because of the presence of PDI (Table 2).

${ }^{29} \mathrm{Si}$ SSNMR spectroscopy is a frequently used technique to examine the chemical nature of $\mathrm{Si}$ atoms in $\mathrm{SiO}_{2}$ [27-29]. As shown in Fig. 3, two peaks are observed in the ${ }^{29} \mathrm{Si}$ SSNMR spectrum of $\mathrm{SN}-\mathrm{NH}_{2}$. The peak around $-110 \mathrm{~nm}$ is assigned to $\mathrm{Si}$ atoms with hydroxyl groups. The peaks from Si atoms with no, one, and two hydroxyl groups appear at $-109,-100$, and -90 ppm, respectively [30]. In this case, only peaks at -109 and
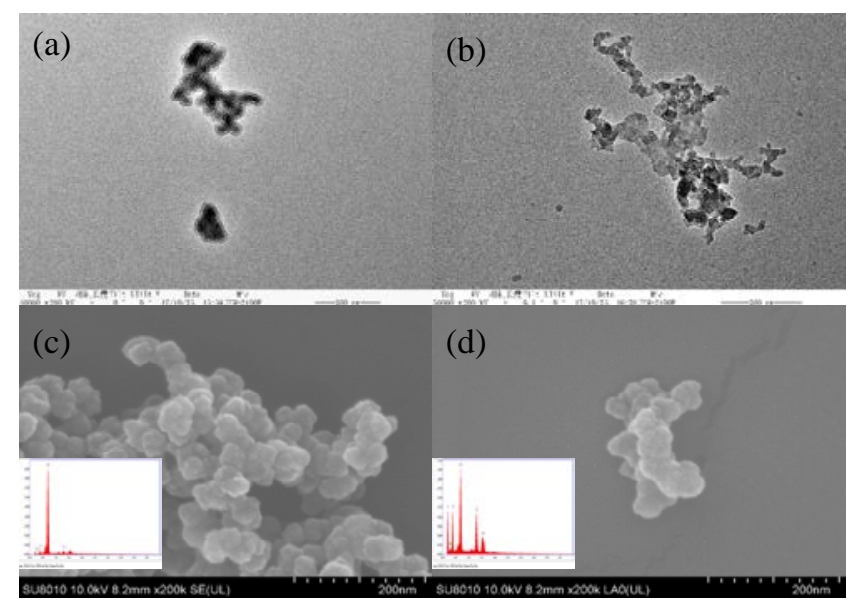

Fig. 1. TEM images of $\mathrm{SN}-\mathrm{NH}_{2}$ (a) and SN-PDI (b), and SEM images (inset: corresponding EDX) of SN-NH 2 (c) and SN-PDI (d).

Table 1

BET and TPV of SN-NH $\mathrm{N}_{2}$ and SN-PDI.

\begin{tabular}{lcc}
\hline Sample & BET $\left(\mathrm{m}^{2} / \mathrm{g}\right)$ & $\mathrm{TPV}\left(\mathrm{cm}^{3} / \mathrm{g}\right)$ \\
\hline SN-NH & & 0.57 \\
SN-PDI & 72.2 & 0.52 \\
\hline
\end{tabular}



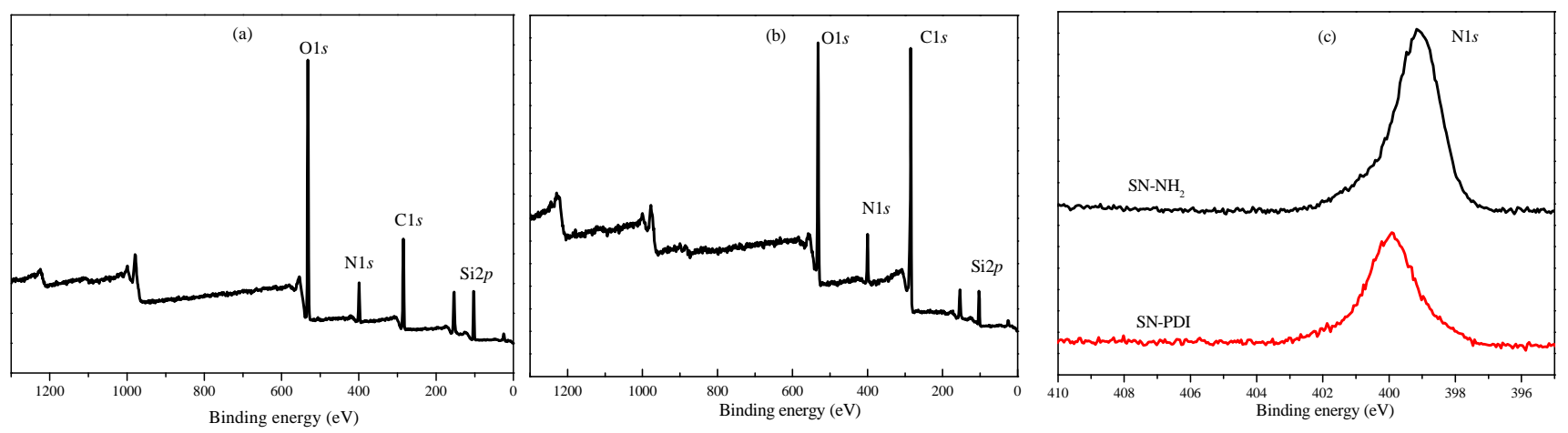

Fig. 2. XPS scans of $\mathrm{SN}-\mathrm{NH}_{2}$ (a) and SN-PDI (b); (c) N 1 s spectra of $\mathrm{SN}-\mathrm{NH}_{2}$ and SN-PDI.

-100 ppm are observed following peak deconvolution, indicating that the most of $\mathrm{Si}$ atoms have no or one hydroxyl group. This result means that most of the $\mathrm{Si}$ atoms are attached together to form a highly condensed network in $\mathrm{SN}^{-\mathrm{NH}_{2}}$. The peak at $-66 \mathrm{ppm}$ is attributed to $\mathrm{Si}$ atoms connected to an amino group [30]. The percentage of $\mathrm{Si}$ atoms with an amino group estimated from the peak areas is $33 \%$ of the total $\mathrm{Si}$ atoms, which is similar to the result obtained by Suratwala et al. [31].

The ${ }^{13} \mathrm{C}$ SSNMR spectrum of SN-NH $\mathrm{N}_{2}$ contains three signals at $44.2,24.8$, and $10.6 \mathrm{ppm}$ that are assigned to the $\mathrm{C}_{\mathrm{a}}, \mathrm{Cb}_{\mathrm{b}}$, and $\mathrm{C}_{c}$ carbon atoms, respectively, of the alkyl chain attached to the amino group (the inset of Fig. 4). These $C_{a}, C_{b}$, and $C_{c}$ signals move to 42.2, 22.7 and $10.0 \mathrm{ppm}$, respectively, in the spectrum of SN-PDI, indicating that the environment of the carbon atoms of the alkyl chain is changed when the amino group attaches to carbonyl groups. The overall shift of these three peaks indicates that most of the surface amino groups of silica react with PTCDA. The signal at $159.8 \mathrm{ppm}$ in the spectrum of PTCDA,

Table 2

Contents of $\mathrm{Si}, \mathrm{O}, \mathrm{C}$, and $\mathrm{N}$ in $\mathrm{SN}-\mathrm{NH}_{2}$ and SN-PDI.

\begin{tabular}{lcccc}
\hline \multirow{2}{*}{ Sample } & \multicolumn{4}{c}{ Atomic content (\%) } \\
\cline { 2 - 5 } & $\mathrm{Si}$ & $\mathrm{O}$ & $\mathrm{C}$ & $\mathrm{N}$ \\
\hline $\mathrm{SN}-\mathrm{NH}_{2}$ & 19.7 & 35.67 & 35.64 & 8.99 \\
SN-PDI & 7.81 & 22.61 & 62.48 & 7.11 \\
\hline
\end{tabular}

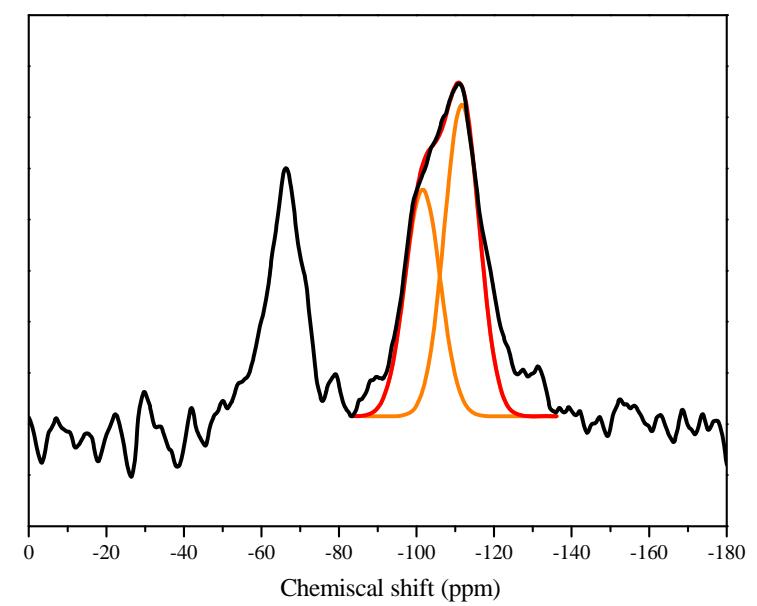

Fig. 3. ${ }^{29} \mathrm{Si}$ SSNMR spectrum of SN-NH2. which is assigned to the $\mathrm{C}_{\mathrm{d}}$ carbon atom is shifted to $162.3 \mathrm{ppm}$ in the spectrum of SN-PDI, indicating the oxygen atom in the acid anhydride is replaced by a nitrogen atom; that is, PDI bound covalently to the nano- $\mathrm{SiO}_{2}$ surface.

The structures of the obtained $\mathrm{SN}-\mathrm{NH}_{2}$ and SN-PDI were further investigated by FT-IR spectroscopy. As shown in Fig. 5, for $\mathrm{SN}-\mathrm{NH}_{2}$, the absorptions near 1646 and $800 \mathrm{~cm}^{-1}$ are caused by the Si-OH vibration [31,32]. The absorption near $2940 \mathrm{~cm}^{-1}$ is attributed to the $-\mathrm{CH}_{2}$ stretching vibration [31,32] and that near $1548 \mathrm{~cm}^{-1}$ is from the $\mathrm{N}-\mathrm{H}$ bending vibration. The FT-IR spectrum of SN-PDI does not contain a peak at 1548 $\mathrm{cm}^{-1}$, indicating that the reaction occurred between $\mathrm{SN}-\mathrm{NH}_{2}$ and PTCDA molecules. The FT-IR spectrum of PTCDA displays peaks near 1592 and $1500 \mathrm{~cm}^{-1}$ originating from skeleton vibrations of the aromatic structure; these absorptions are also observed in the FT-IR spectrum of SN-PDI. The FT-IR spectrum of PTCDA also exhibited peaks centered at about $1770 \mathrm{~cm}^{-1}$ attributed to the $\mathrm{C}=\mathrm{O}$ vibration of acid anhydride and near $1300 \mathrm{~cm}^{-1}$ from the $\mathrm{C}-0$ vibration of acid anhydride. When PTCDA was loaded on $\mathrm{SN}-\mathrm{NH}_{2}$ to form SN-PDI, these characteristic absorptions of acid anhydride disappeared and characteristic amide $\mathrm{C}=\mathrm{O}$ and $\mathrm{C}-\mathrm{N}$ absorption peaks appeared at 1670 and $1274 \mathrm{~cm}^{-1}$, respectively, indicating that the PDI structure formed. All of these results show that PDI was successfully anchored on silica through the one-step reaction of $\mathrm{SN}-\mathrm{NH}_{2}$ with PTCDA.

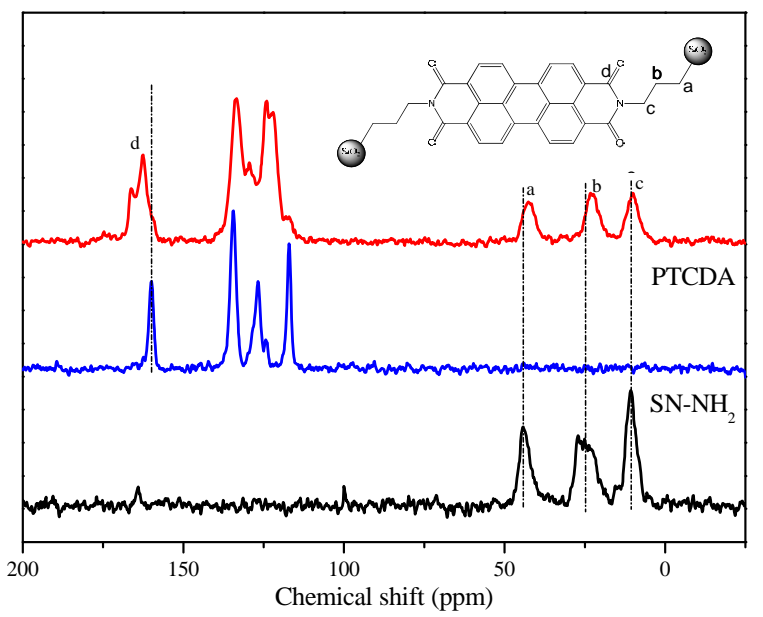

Fig. 4. ${ }^{13} \mathrm{C}$ SSNMR spectra of $\mathrm{SN}-\mathrm{NH}_{2}$ and SN-PDI. For comparison, the spectrum of PTCDA is also shown. Inset: the structure of SN-PDI. 


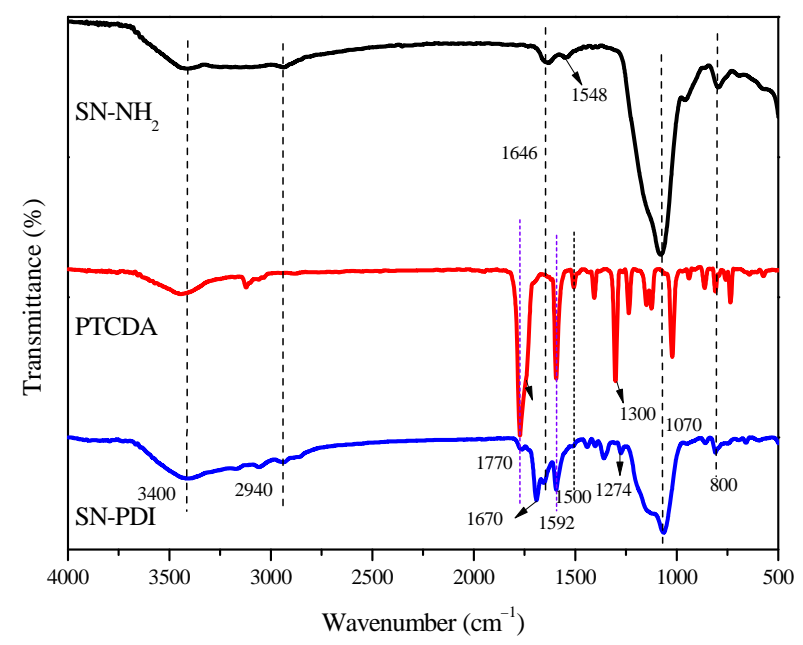

Fig. 5. FT-IR spectra of $\mathrm{SN}-\mathrm{NH}_{2}$, SN-PDI and PTCDA.

The quantity of PDI in SN-PDI was determined by TGA. As shown in Fig. 6, PTCDA begins to lose weight at $550{ }^{\circ} \mathrm{C}$. Nearly all the PTCDA disappeared after heating to $750{ }^{\circ} \mathrm{C}$. The weight loss of SN-NH 2 began at $300{ }^{\circ} \mathrm{C}$, and calcination at $750{ }^{\circ} \mathrm{C}$ led to the loss of $27 \%$ of its weight. After PDI loading, about $48 \%$ weight loss was observed at $750{ }^{\circ} \mathrm{C}$ for SN-PDI. These results indicate that PDI accounts for about $21 \%$ of the weight of SN-PDI.

Comparison on the fluorescence spectra of the supported PDI (SN-PDI) and molecular PDI shows that loading PDI on nano- $\mathrm{SiO}_{2}$ slightly shifted its maximum emission wavelength from 578 to $574 \mathrm{~nm}$ (Fig. 7). This is probably because of the more polar environment of the PDI molecules on the surface of nano- $\mathrm{SiO}_{2}$ than in solution.

\subsection{Photocatalytic activity under visible-light irradiation}

The photochemical reduction of SN-PDI was first examined using TEA as an electron donor in DMF. Before visible-light irradiation, the suspension of SN-PDI was yellow. After removing the SN-PDI by filtration, the solution was colorless, indicating that all the PDI was anchored on nano- $\mathrm{SiO}_{2}$ and no PDI was released into the solution. After irradiation for $30 \mathrm{~min}$, the sus-

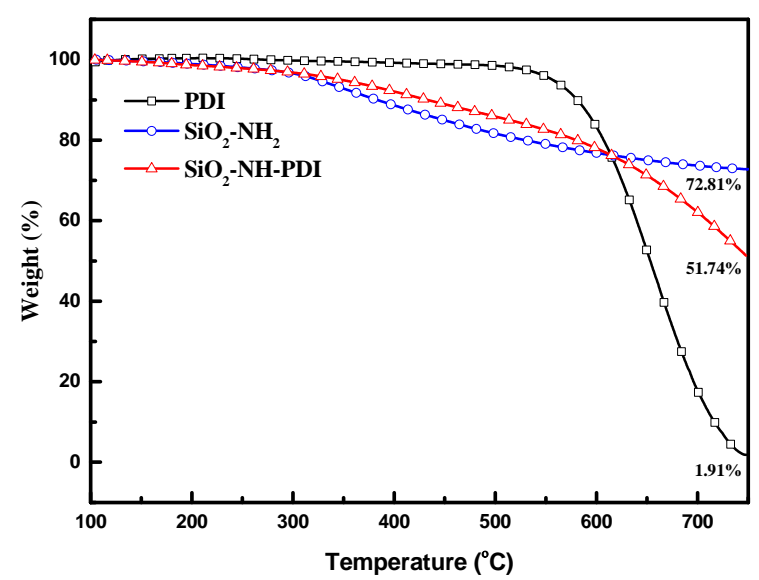

Fig. 6. TGA curves of $\mathrm{SN}-\mathrm{NH}_{2}$, PTCDA, and SN-PDI.

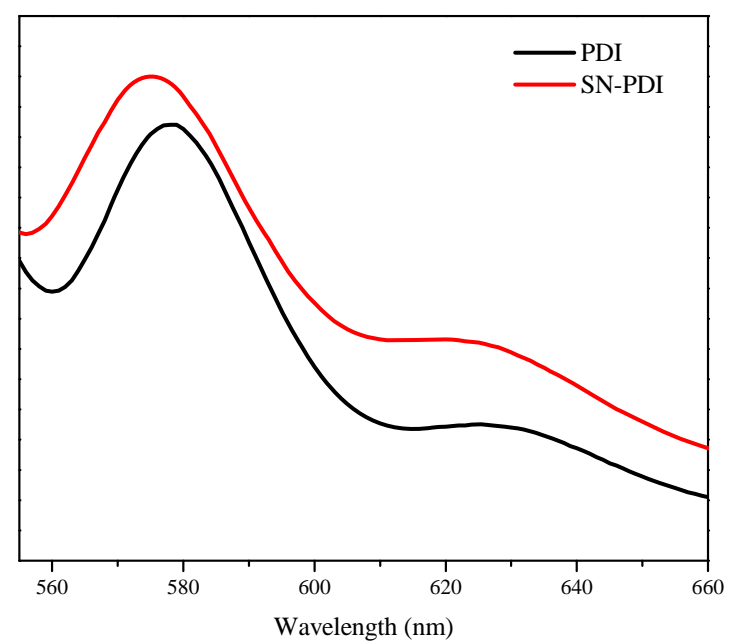

Fig. 7. Fluorescence spectra of SN-PDI and molecular PDI in DMF.

pension became dark blue (Fig. 8), indicating the photochemical reduction of PDI to its radical anion (PDI--). The photochemical activity of the radical anion was investigated by its ability to catalyze the reductive debromination of BDE 209, an important environmental pollutant. It was found that the debromination reaction occurred quite quickly in the DMF solution containing SN-PDI. After irradiation for $0.5 \mathrm{~h}$, all the BDE 209 was removed and polybromodiphenyl ethers with fewer bromine atoms were produced as intermediates (Fig. 9).

To verify the consecutive two-photon photocatalytic behavior of SN-PDI, we first irradiated a deaerated suspension of SN-PDI with TEA to transform the PDI into its radical anion. The subsequent addition of 4-BCP under argon protection did not change the color of the suspension and no 4-BCP was reduced in the dark, indicating that PDI -- cannot directly reduce 4-BCP. However, subsequent irradiation by visible light led to the rapid reduction of $4-\mathrm{BCP}$, which suggests that the excited state of the radical anion can form through the reduction reaction.

To test the photostability of SN-PDI, we repeatedly added 4-BCP to the photocatalytic suspension. After adding 4-BCP three times, the removal rate of 4-BCP still exceeded $70 \%$ following irradiation for $1 \mathrm{~h}$ (Fig. 10), indicating the photocatalytic activity decreased somewhat. In addition, the color of the suspension did not change much, indicating the SN-PDI photocatalyst is quite stable under the photocatalytic conditions.

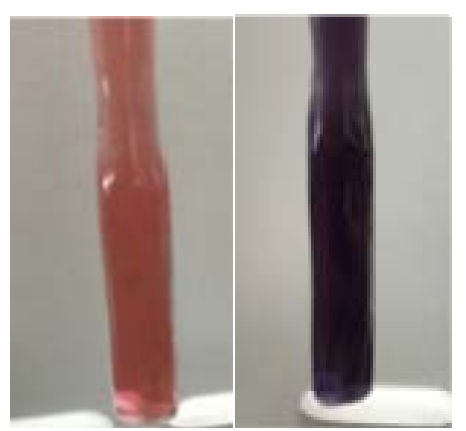

Fig. 8. Color change of a DMF suspension of SN-PDI in the presence of $\mathrm{Na}_{2} \mathrm{~S}$ during visible-light irradiation for $30 \mathrm{~min}$. 


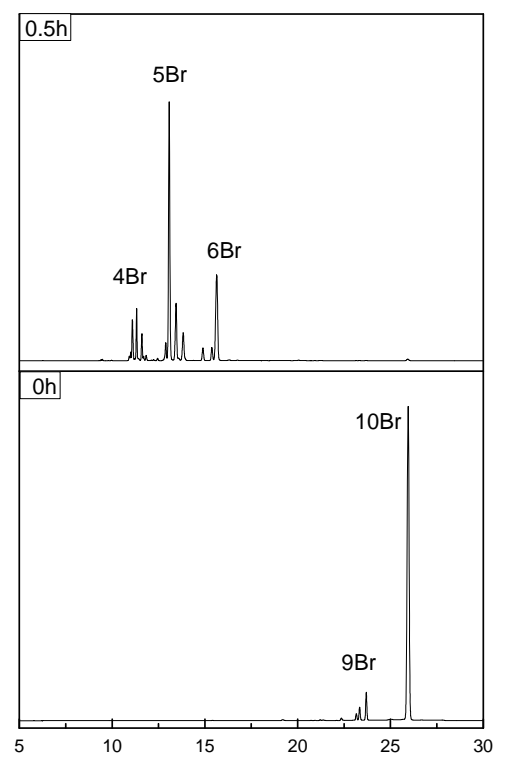

Fig. 9. Photocatalytic reduction of BDE 209 by SN-PDI.

To test the photochemical activity of SN-PDI in water, we used 4-BCP as a substrate. In the presence of $\mathrm{Na}_{2} \mathrm{~S}$ as an electron donor, the photocatalytic debromination of 4-BCP occurred efficiently in aqueous solution. After irradiation for $2 \mathrm{~h}$, about $60 \%$ of the original 4-BCP was debrominated to acetophenone. Control experiments in the absence of SN-PDI or $\mathrm{Na}_{2} \mathrm{~S}$ did not show any photochemical reaction under otherwise identical conditions (Fig. 11). This indicates that the debromination reaction is caused by the light absorption of SN-PDI and the electron donor is important to the photocatalytic reactions. Besides $\mathrm{Na}_{2} \mathrm{~S}$, other common water-soluble electron donors such as methanol and TEA were also tested. However, at natural $\mathrm{pH}$, none of these electron donors were active for the debromination reaction of 4-BCP. One possible explanation for the inertness of these electron donors is their different $\mathrm{pH}$. The solution of $\mathrm{Na}_{2} \mathrm{~S}$ is basic with a high $\mathrm{pH}$ of 9.6 because of the hydrolysis of sulfide anions. To test whether the $\mathrm{pH}$ influenced the photocatalytic reaction, we adjusted the $\mathrm{pH}$ of the $\mathrm{Na}_{2} \mathrm{~S}$ solution. As shown in Fig. 11(b), when the pH of the suspension

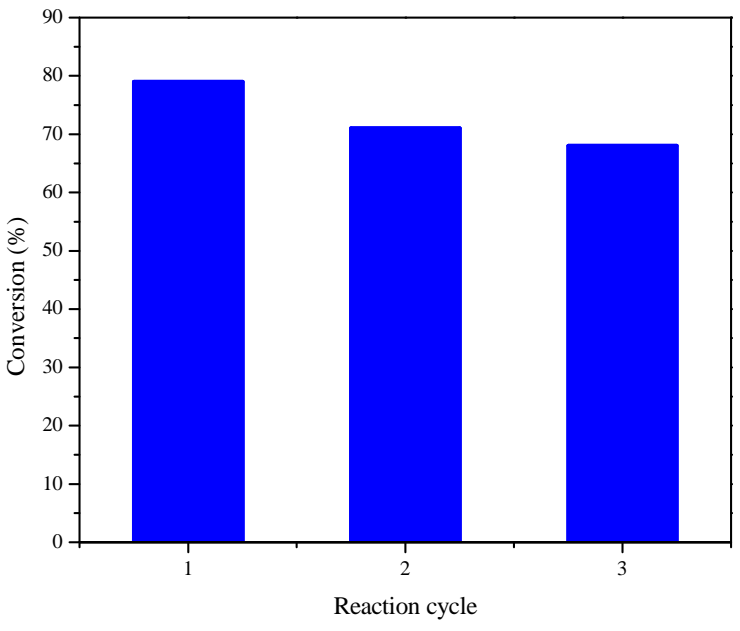

Fig. 10. Photostability of the SN-PDI photocatalyst tested by repeatedly adding BDE 209 to the same reaction mixture.

was adjusted from the natural $\mathrm{pH}(\mathrm{pH}=10)$ to $\mathrm{pH}=6$ or 8 , the photocatalytic reaction was completely suppressed. In contrast, adjusting the $\mathrm{pH}$ of the suspension to 10 in the presence of methanol or TEA as an electron donor allowed the debromination reaction to occur smoothly. All these results suggest that basic conditions are needed for the successful photocatalytic reaction of SN-PDI in water.

To shed light on mechanism behind the effect of $\mathrm{pH}$ on the photocatalytic reaction, we investigated the change of visible light spectra after irradiation, which provided information about on the photochemical formation of $\mathrm{PDI} \bullet^{-}$. As shown in Fig. 12, the irradiation of the deaerated aqueous suspension of SN-PDI in the presence of $\mathrm{Na}_{2} \mathrm{~S}$ at $\mathrm{pH} 10$ leads to the appearance of a broad absorption peak around $750 \mathrm{~nm}$, which is assigned to the formation of PDI ${ }^{-}$. In addition, in the presence of 4-BCP, the peak from PDI ${ }^{--}$was not observed. By contrast, at $\mathrm{pH}=8$, no photochemical reaction was observed during the irradiation, even in the absence of 4-BCP, indicating that $\mathrm{PDI} \cdot-$ did not form under these conditions. It has been reported that the photocatalytic dehalogenation reaction by PDI proceeds through a two-proton, two-electron transfer process. In the

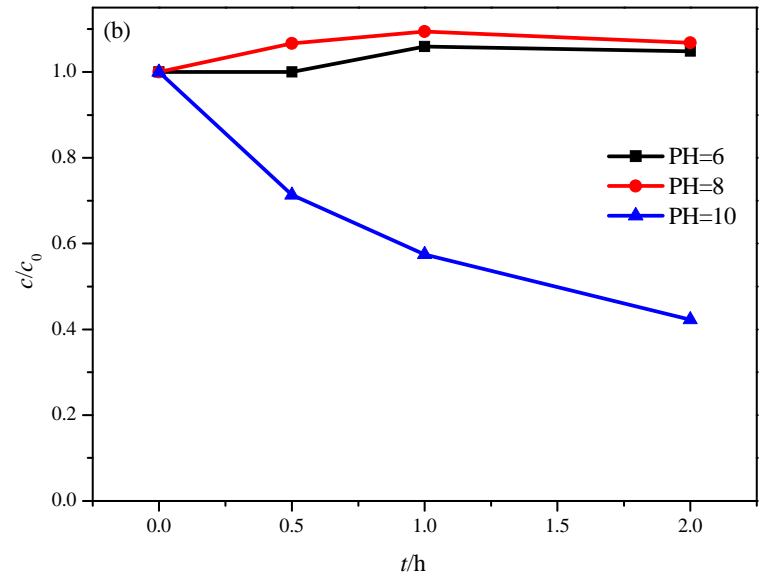

Fig. 11. (a) Photocatalytic reduction of 4-bromoacetophenone in the presence of SN-PDI ( $1 \mathrm{~g} / \mathrm{L})$ and $\mathrm{Na}_{2} \mathrm{~S}$ (1 mmol/L), only SN-PDI, and only Na $2 \mathrm{~S}$; (b) The effect of $\mathrm{pH}$ on the photocatalytic reduction of 4-bromoacetophenone. 

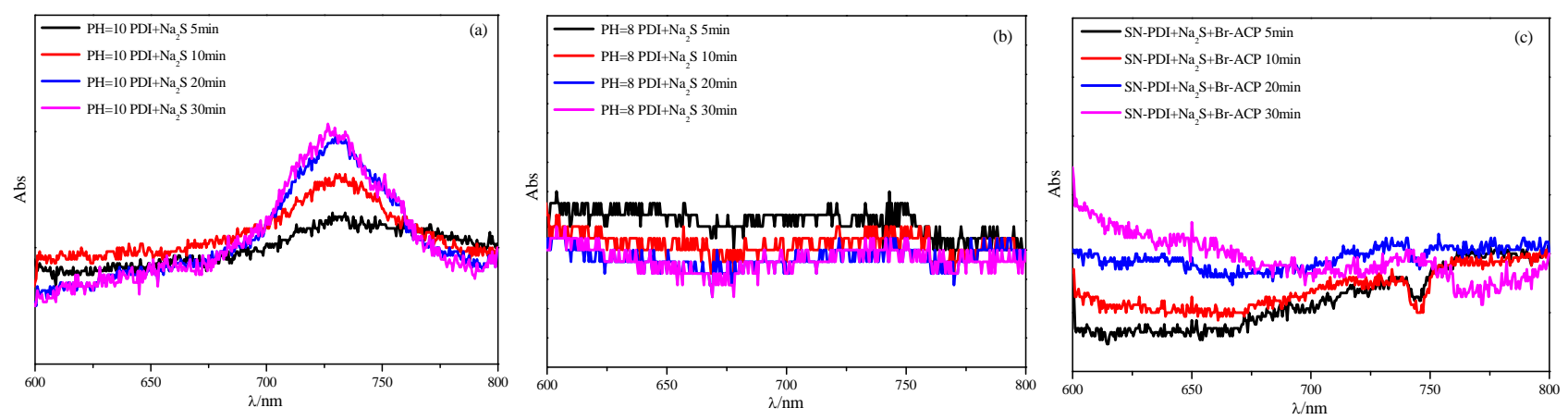

Fig. 12. Change in UV-vis absorption spectra of aqueous suspensions of SN-PDI in the presence of $\mathrm{Na}_{2} \mathrm{~S}$ at $\mathrm{pH}=10$ (a) and $\mathrm{pH}=8$ (b); (c) After 4-bromoacetophenone was added to the system in (a).

first step, PDI absorbs a photon and abstracts an electron from an electron donor to produce the relatively stable PDI ${ }^{--}$. In the second step, the formed PDI*- is further excited by a second proton to produce an excited state with high enough reductivity to reduce the aryl halide. The observation that no PDI -- is formed at $\mathrm{pH}=8$ suggests that the ineffectiveness of SN-PDI at low $\mathrm{pH}$ results from the prevention of the first step.

\section{Conclusions}

PDI was anchored on the surface of nano-SiO ${ }_{2}$ by reaction of $\mathrm{SN}-\mathrm{NH}_{2}$ with PTCDA. Characterization of the SN-PDI photocatalyst showed that PDI was linked on the nano- $\mathrm{SiO}_{2}$ surface through covalent chemical bonds. The SN-PDI photocatalyst retained the consecutive two-photon photocatalytic behavior of PDI, which enabled it to catalyze a photoreduction reaction that is thermodynamically unfavorable via a single-photon process. The present study provides a promising heterogeneous PDI photocatalyst that overcomes the intrinsic restriction of the low solubility of PDI while keeping its consecutive two-photon photocatalytic feature.

\section{References}

[1] M. S. Akple, J. Low, Z. Qin, S. Wageh, A. A. Al-Ghamdi, J. Yu, S. Liu, Chin. J. Catal., 2015, 36, 2127-2134.

[2] Y. F. Li, W. P. Zhang, X. Shen, P. F. Peng, L. B. Xiong, Y. Yu, Chin. J. Catal., 2015, 36, 2229-2236.

[3] T. J. Wu, X. D. Kang, M. W. Kadi, I. Ismail, G. Liu, H. M. Cheng, Chin. J. Catal., 2015, 36, 2103-2108.

[4] M. L. Marin, L. Santos-Juanes, A. Arques, A. M. Amat, M. A. Miranda, Chem. Rev., 2011, 112, 1710-1750.

[5] A. Graml, I. Ghosh, B. König, J. Org. Chem., 2017, 82, 3552-3560.

[6] C. K. Prier, D. A. Rankic, D. W. MacMillan, Chem. Rev., 2013, 113, 5322-5363.

[7] F. Teplý, Collect. Czech. Chem. Commun., 2011, 76, 859-917.

[8] X. C. Wang, K. Maeda, A. Thomas, K. Takanabe, G. Xin, J. M. Carlsson, K. Domen, M. Antonietti, Nat. Mater., 2009, 8, 76-80.

[9] J. Zhang, X. F. Chen, K. Takanabe, K. Maeda, K. Domen, J. D. Epping, X. Fu, M. Antonietti, X. Wang, Angew. Chem. Int. Ed., 2010, 49, 441-444.

[10] C. Gonzalez, H. B. Schlegel, J. Phys. Chem., 1990, 94, 5523-5527.

[11] S. Yanagida, A. Kabumoto, K. Mizumoto, C. Pac, K. Yoshino, J. Chem. Soc., Chem. Commun., 1985, 474-475.

\section{Graphical Abstract}

Chin. J. Catal., 2017, 38: 2094-2101 doi: 10.1016/S1872-2067(17)62960-7

\section{Synthesis, characterization, and activity of a covalently anchored heterogeneous perylene diimide photocatalyst}

Jinting Shang, Hanying Tang, Hongwei Ji, Wanhong Ma, Chuncheng Chen*, Jincai Zhao

Institute of Chemistry, Chinese Academy of Sciences;

University of Chinese Academy of Sciences

By loading covalently PDI molecules on nano-silica, a heterogeneous PDI photocatalyst (SN-PDI) was developed, which can absorb two photons to reduce the halogenated substrates in common solutions, even in water.

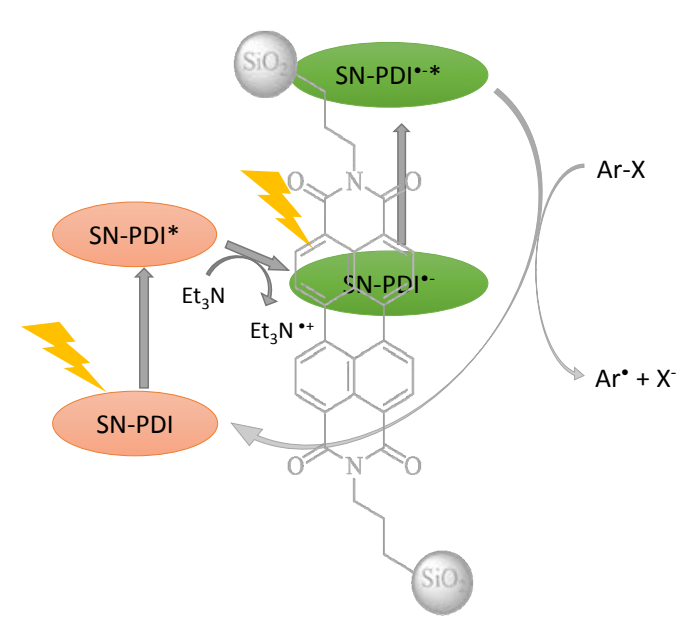


[12] B. Lin, C. Xue, X. Q. Yan, G. P. Yang, G. Yang, B. L. Yang, Appl. Surf. Sci., 2015, 357, 346-355.

[13] C. J. Hao, J. Li, Z. L. Zhang, Y. J. Ji, H. H. Zhan, F. X. Xiao, D. Wang, B. Liu, F. B. Su, Appl. Surf. Sci., 2015, 331, 17-26.

[14] S. Phanichphant, A. Nakaruk, D. Channei, Appl. Surf. Sci., 2016, 387, 214-220.

[15] X. F. Wang, R. Yu, K. Wang, G. Q. Yang, H. G. Yu, Chin. J. Catal., 2015, $36,1211-2218$.

[16] F. Würthner, Chem. Commun., 2004, 1564-1579.

[17] K. Takahashi, I. Nakajima, K. Imoto, T. Yamaguchi, T. Komura, K. Murata, Solar Energy Mater. Solar Cells, 2003, 76, 115-124.

[18] L. Schmidt-Mende, A. Fechtenkötter, K. Müllen, E. Moons, R. H. Friend, J. MacKenzie, Science, 2001, 293, 1119-1122.

[19] X. W. Zhan, Z. A. Tan, B. Domercq, Z. S. An, X. Zhang, S. Barlow, Y. F. Li, D. B. Zhu, B. Kippelen, S. R. Marder, J. Am. Chem. Soc., 2007, 129, $7246-7247$.

[20] I. Ghosh, T. Ghosh, J. I. Bardagi, B. Konig, Science, 2014, 346, 725-728.

[21] S. Guha, F. S. Goodson, S. Roy, L. J. Corson, C. A. Gravenmier, S. Saha, J. Am. Chem. Soc., 2011, 133, 15256-15259.

[22] F. Ronconi, Z. Syrgiannis, A. Bonasera, M. Prato, R. Argazzi, S. Caramori, V. Cristino, C. A. Bignozzi, J. Am. Chem. Soc., 2015, 137,
4630-4633.

[23] D. Liu, J. Wang, X. J. Bai, R. L. Zong, Y. F. Zhu, Adv. Mater., 2016, 28, 7284-7290.

[24] L. Zeng, T. Liu, C. He, D. Y. Shi, F. L. Zhang, C. Y. Duan, J. Am. Chem. Soc., 2016, 138, 3958-3961.

[25] I. A. Rahman, M. Jafarzadeh, C. S. Sipaut, Ceram. Int., 2009, 35, 1883-1888.

[26] H. X. Tang, P. Liu, M. Lu, Y. F. Ding, F. Wang, C. Gao, S. M. Zhang, M. S. Yang, Polymer, 2017, 112, 369-376.

[27] M. C. Brochier Salon, P. A. Bayle, M. Abdelmouleh, S. Boufi, M. N. Belgacem, Colloids Surf. A, 2008, 312, 83-91.

[28] K. Albert, R. Brindle, J. Schmid, B. Buszewski, E. Bayer, Chromatographia, 1994, 38, 283-290.

[29] R. Brambilla, G. P. Pires, J. H. dos Santos, M. S. Lacerda Miranda, J. Colloid Interface Sci., 2007, 312, 326-332.

[30] S. Chen, S. Hayakawa, Y. Shirosaki, E. Fujii, K. Kawabata, K. Tsuru, A. Osaka, J. Am. Ceram. Soc., 2009, 92, 2074-2082.

[31] T. I. Suratwala, M. L. Hanna, E. L. Miller, P. K. Whitman, I. M. Thomas, P. R. Ehrmann, R. S. Maxwell, A. K. Burnham, J. Non-cryst. Solids, 2003, 316, 349-363.

[32] T. Suteewong, H. Sai, M. Bradbury, L. A. Estroff, S. M. Gruner, U. Wiesner, Chem. Mater., 2012, 24, 3895-3905.

\title{
异相光催化剂菲酰亚胺的合成、表征及活性
}

\author{
商锦婷 ${ }^{\mathrm{a}, \mathrm{b}}$, 唐瀚泳 ${ }^{\mathrm{a}, \mathrm{b}}$, 籍宏伟 ${ }^{\mathrm{a}, \mathrm{b}}$, 马万红 ${ }^{\mathrm{a}, \mathrm{b}}$, 陈春城, ${ }^{\mathrm{a}, \mathrm{b},{ }^{*}}$, 赵进才 ${ }^{\mathrm{a}, \mathrm{b}}$ \\ a中国科学院化学研究所光化学院重点实验室, 北京100190 \\ 中国科学院大学, 北京 100049
}

摘要: 光催化是催化反应中非常重要的一个领域, 其中可见光催化反应在实际应用中尤为重要. 近几十年, 众多研究者致 力于可见光催化剂的研究, 如有机染料、有机金属复合物和共价有机聚合物等都是常见的可见光催化剂. 近年来, 人们发 现菲酰亚胺(PDI)是一类活性非常高的可见光催化剂, 因为一个PDI分子可以连续吸收两个光子而积累足够的能量, 使得许 多单光子过程能量不足以激发的反应能够顺利进行. 然而, 由于PDI结构中存在大共轭的苯环, 其在大部分溶剂中的溶解 度都比较低, 尤其是在水相中很难溶解, 因此限制了它的应用.

本文将PDI分子通过共价键键合在纳米二氧化硅表面, 合成了一种新的多相PDI光催化剂(SN-PDI), 解决了PDI在很多 溶剂中都难以分散的问题, 同时保留了它双光子吸收的光催化特性. 我们首先合成了表面修饰有氨基的纳米二氧化硅, 然 后与倸䣶反应, 从而将PDI键合在二氧化硅表面. 利用二氧化硅的亲水性使得PDI在水中以及大部分溶剂中很好地分散和 分离, 从而充分发挥PDI的光催化还原性能.

通过 ${ }^{29} \mathrm{Si}$ 固体核磁(NMR)、X 射线光电子能谱(XPS)、 ${ }^{13} \mathrm{C}$ 固体核磁、傅里叶变换红外光谱(FT-IR)、紫外-可见吸收光谱 以及热重分析等手段表征了合成后的SN-PDI. 其中 ${ }^{29} \mathrm{Si}$ 固体核磁谱图中化学位移在-66 ppm处的峰证明了缩合形成的纳米 二氧化硅中带有氨基, 根据峰面积得到其中 $33 \%$ 的硅原子上连有氨基. XPS结果发现, N $1 \mathrm{~s}$ 轨道有明显位移, 说明合成后 $\mathrm{N}$ 原子的化学环境发生了明显变化. ${ }^{13} \mathrm{C} N \mathrm{NR}$ 结果表明, 合成前后与氨基相连的几个碳也发生了较大位移, 与理论一致. FT-IR发现萠酐中酸酐特征峰消失以及亚胺特征峰出现, 证明PDI成功键合在了二氧化硅表面.

以十澳联苯醚和4-溴苯乙酮作为卤代底物, 分别在有机相和水相中采用SN-PDI光催化降解反应, 结果均得到了脱卤后 的产物. 催化剂循环三次仍有较高活性. 可见, 键合在纳米二氧化硅表面的PDI确实具有光催化活性.

关键词: 可见光; 光催化; 纳米二氧化硅; 菲酰亚胺; 脱卤

收稿日期: 2017-10-18. 接受日期: 2017-11-01. 出版日期: 2017-12-05.

*通讯联系人. 电子信箱: ccchen@iccas.ac.cn

基金来源：国家自然科学基金(21525729, 21590811, 21521062, 2177168); 中国科学院战略性先导科技专项(XDA09030200); 中国 科学院创新交叉团队项目.

本文的电子版全文由Elsevier出版社在ScienceDirect上出版(http://www.sciencedirect.com/science/journal/18722067). 